This item was submitted to Loughborough's Research Repository by the author.

Items in Figshare are protected by copyright, with all rights reserved, unless otherwise indicated.

\title{
Perceptions of labour market risks: shifts and continuities across generations
}

PLEASE CITE THE PUBLISHED VERSION

http://dx.doi.org/10.1177/0011392110385968

PUBLISHER

SAGE Publications for the International Sociological Association ( The Author(s)

VERSION

AM (Accepted Manuscript)

LICENCE

CC BY-NC-ND 4.0

REPOSITORY RECORD

Predelli, Line Nyhagen, and Andreas Cebulla. 2019. "Perceptions of Labour Market Risks: Shifts and Continuities Across Generations". figshare. https://hdl.handle.net/2134/13373. 
This item was submitted to Loughborough's Institutional Repository (https://dspace.lboro.ac.uk/) by the author and is made available under the following Creative Commons Licence conditions.

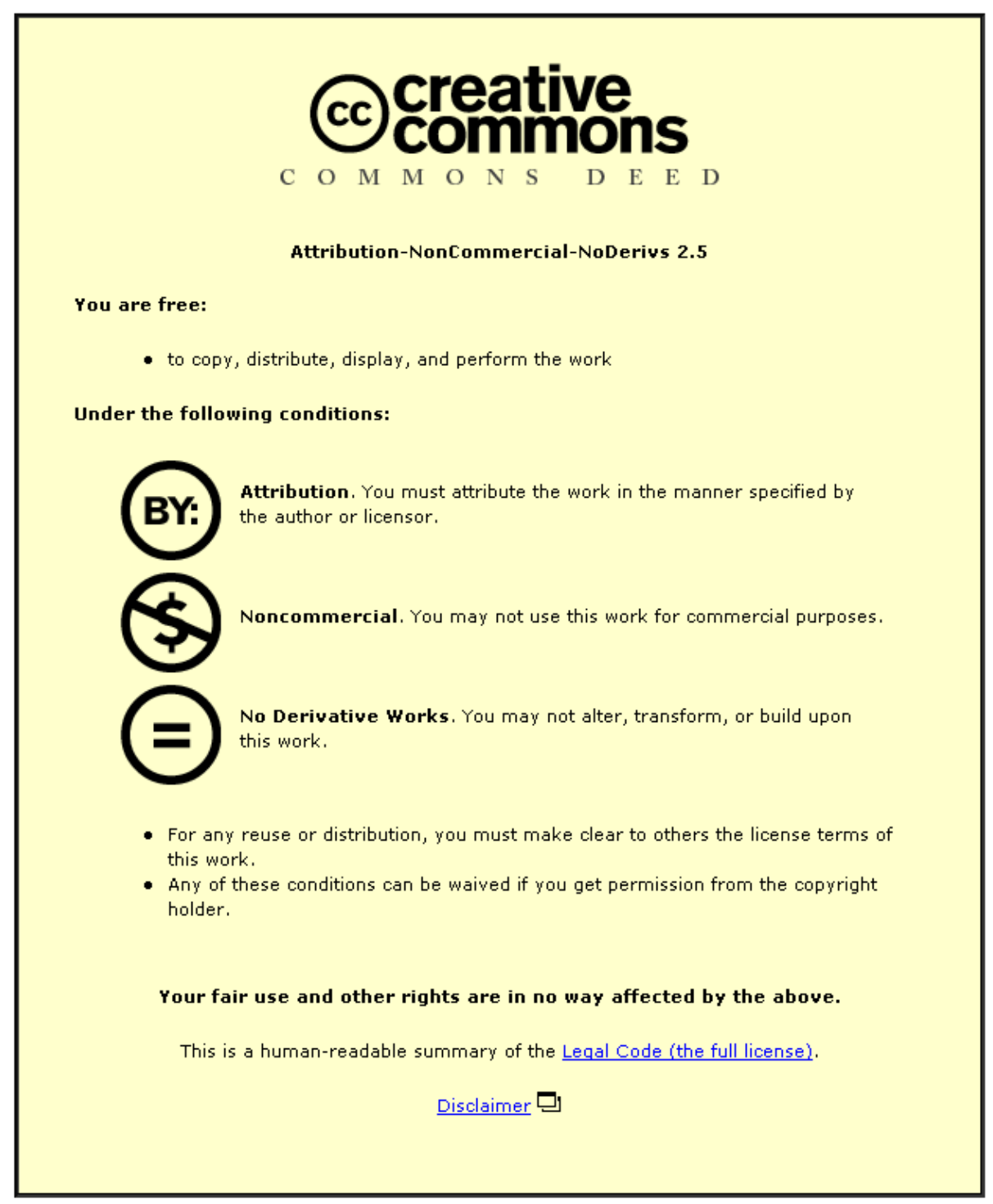

For the full text of this licence, please go to: http://creativecommons.org/licenses/by-nc-nd/2.5/ 


\section{Perceptions of Labour Market Risks: Shifts and Continuities across Generations}

\section{By Line Nyhagen Predelli and Andreas Cebulla}

\section{Introduction}

Grand theories of increasing levels of individualisation and risk in modern society have been forwarded most notably by Beck (1992) and Giddens (1991). For Beck, an all-pervasive sense of risk has become a ubiquitous feature of life in both public and private domains. Individuals are seen as required to negotiate and plan their own actions and pathways in environments where known and unknown, objective and subjective risks pose potential threats to their sense of identity, belonging and well-being. Beck defines individualisation as a process in which 'each person's biography is [being] removed from given determinations and placed in his or her own hands, open and dependent on decisions' (Beck 1992: 135). Each individual is thus becoming responsible for his or her own future life chances, choices and options, and the continuous creation and construction of the self can be viewed as an on-going DIY project (Kelly 2001: 26; Beck 2000: 75). The notion that the individual is solely responsible for his or her own life chances and decision-making implies a heightened subjective sense of risk, as possible courses of action are numerous and include options that, if chosen, may have a detrimental effect on the life chances and social mobility of the individual. The reverse side of the coin is that individualised responsibility may function in a liberating sense, giving the individual the 
opportunity to realise personal aspirations, make decisions and take risks that positively affect his or her life chances and social mobility. In this sense, as Tulloch and Lupton (2003: 18-19) emphasise, risk does not necessarily represent danger or loss of control, as it can also provide individuals with opportunities that may enhance or improve their well-being. Importantly, Beck's argument does not imply full individual autonomy. Although the individual is 'removed from traditional commitments and support relationships', these are exchanged for constraints produced by the labour market and consumerism (Beck 1992: 131). 'The place of traditional ties and social forms (social class, nuclear family) is taken by secondary agencies and institutions, which stamp the biography of the individual and makes that person dependent upon fashions, social policy, economic cycles and markets...' (ibid.). There is thus an inherent contradiction in the individualisation process between an individual's expectation of being able to plan and control his or her own life on the one hand, and the limitations that are placed, on the other hand, on this ability by external societal factors. In relation to the labour market and the sphere of work, Beck posits that increasing individualisation will bring along new chances and freedom for individuals to carve out their roles, but 'new trapdoors' may limit opportunities and lead to marginalisation and exclusion (Beck 2000: 53). The bottom line is, according to Beck, that 'risks are shifted from the state and the economy on to the shoulders of individuals', thus underlining a 'new precariousness of work' (ibid.: 53-54). In Beck's storytelling, there is a clear disjuncture within modernity itself between the two phases of a 'collectivised' past and an individualised present, where the first phase, described as a 'Fordist regime', 
introduced standardisation, mass production and full employment (Beck 2000: 68). Security, certainty and clearly defined boundaries are said to describe life in the Fordist regime, where families and communities were responsible for interpreting 'opportunities, dangers [and] biographical uncertainties' (Beck and Beck-Gernsheim 2002: 4). The risk regime of the second phase of modernity, however, 'firmly rules out, beyond a transition period, any eventual recovery of the old certainties of standardized work [and] standard life histories...' (Beck 2000: 70). Moreover, the burden of interpreting 'opportunities, dangers [and] biographical uncertainties' has shifted from families and communities onto the individual who, by necessity, develops a heightened sense of risk and responsibility.

Beck and Beck-Gernsheim (2002: 4) suggest that only a comparison of different generations (birth cohorts) will allow a proper assessment of the increase in demands placed on individuals. The changes that have allegedly taken place across cohorts in this respect are however illustrated by Beck and Beck-Gernsheim by reference to two novels written by Michael Cunningham (1991) and Scott Turow (1991), respectively. Together, the quotes taken from these works of fiction present a picture of a 'simple' past where all individuals shared the same dreams and desires and thus followed well-trodden paths, in contrast to a more complex present where individuals have to weigh different alternative courses of action and make their own choices and decisions. Our research, based on interviews with different generations of individuals, allows us in this paper to examine new empirical evidence and to ask how clearly the posited disjuncture between a collectivised past and an individualised present can be identified in biographical narratives about labour market entry and 
participation across these generations. As such, our research can be viewed as a response to the often-presented charge that the risk society thesis lacks empirical verification (Alexander 1996; Wilkinson 2001; Tulloch and Lupton 2003; Mythen 2004 and 2005; de Beer 2007). Moreover, our research adds to the growing academic literature which underlines that risk perceptions are mediated and differentiated along cultural and social-structural lines. Cultural theorists argue that perceptions of risk are culturally constructed and mediated, and subject to social learning (Douglas and Wildawsky 1982; Oltedal et al. 2004). Social theorists highlight how social class, gender, ethnicity and age have a bearing on people's perceptions of and responses to risk - making them, for example, more or less risk-averse (Furlong and Cartmel 1997 and 2007; Lupton 1999, Tulloch and Lupton 2003; Mitchell et al. 2001; Wilkinson 2001; Mythen 2005). Our research adds an important dimension to such theoretical and empirical nuances by focusing explicitly on inter-generational changes and continuities in risk perceptions.

\section{Inter-generational risk perceptions and the labour market}

Both Giddens and Beck have placed the emergence of risk society in historical, Western European time in or around the 1950s. Around that time social and economic structures began to mutate in ways that would ultimately bring about a reconstituted social order. The new order placed risk at the centre of social functioning; not as risk calculation and assessment (although both are clearly permeating society today), but as uncertainty, which undermines any notion of the calculability of risk probabilities and makes it 
increasingly difficult for the individual to anticipate (and thus plan) his or her future.

The purpose of our inter-generational study of personal accounts of labour market entry and participation was to investigate continuity and discontinuity in risk perceptions and responses between parents and their adult offspring, and thus to gain an empirically underpinned understanding of the nature, scale and reach of this potentially historical social change. The study responds to Beck's risk society thesis - that we have entered a new era of individualisation and pervasive perceptions of risk - through an analysis of interviews with individuals from different generations about their sense of opportunities and constraints in relation to entering the labour market and changing employment during the life-course. It is thus concerned with social structures, the individuals' awareness and perception of these structures, and the opportunities and/or constraint they are perceived to have offered or presented.

In the risk society thesis, the labour market is seen to have a key role in the production of processes of individualisation (Beck and Beck-Gernsheim 2002). While the 1950 s and 1960 s are perceived as a 'traditional' modern society, in the sense that family and personal networks played a key role in access to and mobility within the labour market, the 1970s and onwards are perceived as a modern 'risk regime' which requires each individual to be responsible for his or her own choices in relation to a labour market which no longer accommodates employment based on kinship and friendship (see Beck 2000). Our sample of two generations of individuals facilitates an 
examination of these purported changes in terms of entry to and participation in the labour market.

If a radical disjuncture in the social positioning of the individual from modern to risk society has indeed occurred, we would expect to find discontinuity between trajectories buttressed by traditional support networks, more typical among the parent generation, and the more individualised biographies emphasising self-reliance and risk, more typical for the off-spring generation. We would also expect a break or evolution in the typical personalised response mechanisms - reflexivity as reflex or reaction (see our next section) - to be observed between the generations. Exploring continuities and discontinuities between parents and their offspring also allows us to consider the influence and 'transfer' of perceptions across family generations. There is a wealth of research literature on intergenerational relationships and intergenerational transmission (see Scabini and Marta 2006 for an overview), but to date there is very little research on the intergenerational transmission of attitudes to risk and uncertainty. One notable exception is that of Dohmen et al. (2006), who used a large scale, representative survey in Germany and found that there is a strong correlation between parents' willingness to take risks and that of their children. Dohmen and colleagues focused on car driving, financial matters, sports and leisure, career, and health, and found that transmission from parent to child is relatively specific and detailed (and thus not only encompassing the transfer of more general attitudes towards risk). Our qualitative research adds to the knowledge currently being developed around intergenerational relationships and the transmission of attitudes to and perceptions of risk. 


\section{Reflexivity as planned reactions or unplanned reflexes}

Although Beck and Giddens essentially agree in their understanding of the material foundations of risk society, they offer somewhat different perspectives on the human responses to perceived or experienced social risk. Their disaccord, which centres on the sociological use of a core element of risk theory, that of 'reflexivity', remains useful as an analytical tool that sheds light on the 'true' nature of our ability to cope with perceived risk. For Giddens, reflexivity signifies the self-aware assessment of behavioural options and the ability to reconcile internal and external demands and influences in order to maintain a coherent personal narrative, if necessary by self-correcting earlier decisions 'on reflection' of their appropriateness (Giddens 1991). Beck, in contrast, certainly in his earlier writings (Beck 1992), understood reflexivity as a spontaneous reaction to unforeseen threats, opportunities and situations that presented choices and required decisions. Unlike Giddens, who perceived reflexivity as purposeful (re-)actions to events (and as responsive to context), the early Beck perceived reflexivity as very much unplanned - a reflex rather than an act of reflecting. Whereas Giddens' notion of reflexivity assumes an individual's ability to know, judge and weigh options before taking decisions, in Beck's use of the term, decision-making may be ad-hoc and preceding judgement and the weighing of options. For the theory and practice of individualisation, these opposing interpretations of 'reflexivity' have correspondingly opposing effects, as one all but rules out long-term strategic behaviours whereas the other retains them at its core. One implies a 'structured randomness' of behaviour, where behaviour is shaped by new 
institutions of control that have replaced traditional (kinship) ties; the other proclaims scope for planned and learned behaviour.

In early modern 'pre-risk' society, reflexivity as (planned) action would have been the privilege of a ruling class of educated and endowed men (more so than women), whilst in late modern risk society, the privilege has become a generalised pre-condition not just for obtaining autonomy and status, but also a sustained livelihood in the face of declining networks of collective support. Re-flex, on the other hand, has evolved and arisen in a new form; as a mode for responding to threats and to choices and opportunities that, in the past, would not have existed or, if they did, would have been addressed and managed according to tradition and kinship rules that have since been losing significance. Re-flex and re-action thus represent different response modes to the uncertain events and outcomes in a society that increasingly manufactures its own risks. As behavioural concepts, they are useful tools for exploring possible experiential divides between generations.

\section{Research Methodology}

We conducted a total of 58 in-depth interviews for our study of intergenerational perceptions and experiences of risk in relation to labour market entry and participation. The interviews were with 29 pairs of parents and their adult children of the same sex (i.e., mothers and daughters, fathers and sons). Gender differences in risk perceptions and experiences are well documented (Gustafson 1998). Moreover, the gender disparities in the nature and extent of change in career structures and opportunities over the last fifty years (see MacEwen Scott 1994) may be expected to impact on 
intergenerational perceptions of career planning and risk. Our interviews therefore involved same-sex inter-generational pairs rather than mixed pairs. We interviewed a total of 16 female pairs and 13 male pairs. In addition to an emphasis on gender balance, the recruitment of interviewees also considered their socio-economic backgrounds. We thought it essential that one of each pair had either changed jobs or been made redundant or experienced unemployment in the last two years, as such events are likely to trigger important decision-making processes.

The actual sample consisted of 29 parent generation individuals aged 38-80, with most (20 individuals) aged in their sixties and seventies, and 29 offspring generation individuals aged 17-53, with most (26 individuals) aged in their twenties, thirties and forties. The age profiles can be mapped onto the 1950s break line that Giddens and Beck have suggested as indicative of the turning point in the emergence of risk society: Roughly half of the parent generation had typically completed their education and started work before or not long into the 1950s, while the other half did so either in the latter half of the 1950s, in the 1960s, or the early 1970s. Members of the offspring generation, on the other hand, typically started this process either in the late 1970s, in the 1980s, or the early 1990 s.

Mirroring the socio-economic changes of the latter half of the twentieth century, the educational and occupational profiles of the parent and the offspring generations differed markedly. Among the 29 individuals in the parent generation, five had a university degree and two had attended college. A majority of them (22) had left school between the ages of 14 and 16 . Of the 29 individuals in the offspring generation, seven had a university degree while 
two had attended university without achieving a degree, and eight had attended college. Less than half (12 individuals) had left school between the ages of 15 and 18 . There is thus evidence of some upward social mobility in educational terms from one generation to the next among the individuals in our sample. In terms of class background (perceived as occupational status) ${ }^{i}$, a majority (18) of the parent generation were from the working classes (nonmanagerial/non-professional, skilled or unskilled; see Roberts 2001: 28-29), while five were from the middle classes and six had worked themselves up from working to middle class through their employment career. There was some evidence of upward social mobility from one generation to the next in terms of occupational status achievement. A majority (16) of the offspring generation belonged to the middle classes, while ten were from working classes and three worked themselves up from working to middle class through their employment career. Many in the offspring generation are also in their early careers and thus have time to achieve more upward mobility. In sum, a majority of the parent generation were from the working classes and had only completed compulsory education, while a majority of the offspring generation were from the middle classes and roughly half of them had received education beyond compulsory schooling. The interviews were conducted in 2005, and most of the participants lived in the English Midlands. With the exception of one pair, the interviewees were all white. Pseudonyms have been invented to protect the identity of all participants.

The interviews, which were all transcribed, used what can be loosely described as a narrative biographical method (Riessman 1993; Roberts 2002; Heinz and Krüger 2001) to explore participants' careers over their life course, 
with a focus on decision-making. This involved asking participants to 'map out' their entire employment history and subsequently focussing on key moments in their career and decision-making related to those events. We used biographical narratives of career histories and career transitions as an anchor to explore changes in risk perceptions across generations. We did not attempt to predict or determine the extent of influence and transfer of risk perceptions across family generations, but to examine and discuss whether, and the extent to which, the biographical narratives revealed the possibility of such influence and transfer in the context of entry to and participation in the labour market.

In contrast to a more direct approach to the study of risk perceptions, the narrative biographical approach enabled us to 'de-centre' the question of risk in the interview context and to apply a more indirect approach without the a priori construction of risk and uncertainty. Empirical research on risk perceptions is often based on the assumption that risk is a significant dimension of people's worldviews and everyday lives, rather than asking whether this is actually so (see Henwood et al. 2008). An alternative view is that people construct and perceive risks in different ways, and attribute different meanings, values and intensities to risks. In a study of the role of risk in everyday life, Tulloch and Lupton (2003: 19) found that their research participants viewed risk as 'biographical, or different for each individual', and that 'risk is the product of a way of seeing rather than an objective fact'. In our own research interviews, we sought to talk explicitly about risk-related events such as applying for or changing jobs, or being made redundant, without immediately using the term 'risk'. Participants were informed that the research 
was about careers and the decisions people make about their careers. In this sense, a framework for invoking a discussion of risk was offered. However, careers and decision-making were not introduced in the interviews as being, a priori, particularly or inherently associated with risk. The interviews did include questions, for example, about trust in employers and support networks, level of knowledge about future options, and consequences (financial and otherwise) when plans do not work out. This methodology highlighted the interplay between participants' employment history, personal development, family change, and other life events and transitions, so that a holistic view of their life careers could be considered. Importantly, the intergenerational approach allowed us to examine similarities and differences across generations. Although such similarities and differences can be due to variations over the life course, the presence of quite broad age bands within both the parent and offspring generation mitigates the impact of life-course position. Moreover, a study of parents and offspring is useful because it reduces the impact of variations in external factors; for example parents and their children are likely to have similar religious and cultural backgrounds.

\section{Risk and decision-making}

In the following sections we first present and discuss the biographical accounts of the parent generation, before turning to those of their children, whom we will collectively refer to as the offspring generation. Our immediate concern is with grasping the quintessential characteristics of the individual generations' account and their rooting in the respective historical context. Our next concern is to match parents to their children and to make comparisons 
across generations. We will explore circumstances that generate matching and non-matching experiences and, importantly, accounts of these experiences. As will become apparent, while we witnessed both stability and change across generations, it is not only experiences but also their framing or interpretation that frequently separated the generations. This said, in the presentation and discussion of difference and separateness it is important not to loose sight of the, often considerable, overlap between the experiences and accounts of both generations. Both during the interviews and at the analysis stage, when reading stories of the two groups of participants, it became apparent that participants from both generations anchored their accounts in different depths of reflexivity that left room for both mediated re-action and immediate reflex.

Some of our participants mainly presented themselves as planners and active decision-makers. They were individualistic in their outlook, and typically aware of different options available to them in terms of labour market participation. They presented narratives suffused with notions of choice, planning, individual control, action and decision-making. We call them planners. Another group of participants mainly presented themselves as people forced by circumstances beyond their control as they entered the labour market or experienced changes in their labour market participation, such as redundancy, unemployment or changing employer. Whenever possible, people in this group 'played it safe' by relying on what family and friends had done before them - they went into traditional labour market trajectories. They valued a secure income over alternative opportunities and possible instability (we call them safe-players). The narratives from this group were often 
suffused with notions of tradition, limited opportunities and choice, and financial need.

A third and final group of participants mainly presented themselves as highly flexible individuals, or as people who were 'going with the flow' or 'taking one day at a time'. Narratives from this group are characterised by a combination of pre-determined objectives and potential or actual deviations from these, experimentation with perceived options and opportunities, flexibility, and a general lack of worrying about the future (our short-hand for this group is 'surfers'). People in this group may 'surf' when opportunities arise, but might also skip 'a good surf' without much regret. They are very flexible in their outlook, and do not worry much. They are aware of different options but do not necessarily think it's worthwhile to pursue them.

In our analysis of the biographical narratives, we explored the extent to which the actions that individuals had taken (or, in their view, had been forced to take) reflected or contradicted their self-presentation. We also sought to achieve an understanding of how class background, gender and education might have impacted on the biographical narratives presented by the interviewees.

Our sample, of course, only included individuals with an attachment to the labour market, which might itself propagate the value placed on labour market participation. The research participants presented themselves as individuals with a strong work ethic, which included a commitment to provide for the family and a deep hesitation, even resentment, towards becoming dependent on the welfare state, and the feeling that it was important to occupy oneself with daily activities through work. As such, a strong Protestant work ethic and 
attitude towards life (Weber 2001) shone through the biographical narratives. What differed between individuals and between generations, however, were the ways in which individuals entered the labour market, how they made decisions about changes in their employment, and their more general perceptions of risk and control in relation to paid work.

\section{Generational pathways to the labour market: The parent generation}

In most of the biographical stories, either the 'planner', the 'safer' or the 'surfer' narratives were predominant. In some, however, a more mixed selfpresentation and understanding came to the fore, either as a constant complexity or as a marked change over time resulting from life changes or transitions (we revisit this issue later). Typically, members of the parent generation presented narratives in which forces beyond their own control were decisive in relation to their first entry into the labour market. By and large, they were 'safer-players'; twenty of the twenty-nine parent narratives mainly displayed 'safe-player' attitudes and experiences. Only a handful identified as 'surfers', while three individuals in the parent generation represented themselves as a 'planner'. While two of the clear 'planners' among the parents had left school early, one undertook a four-year university degree and became a teacher. All but two of the clear 'safer-players' had left school early, while the 'surfers' in the parent generation displayed a more mixed picture of both early school-leavers and individuals achieving higher education.

Options and choices in terms of future educational and employment opportunities were often quite limited for the parent generation. Many families 
from a manual or working class background, who formed the majority of participants from the older generation in our study, were simply not in a position to support their children through further education beyond compulsory schooling, and for some families it was a question of sending their children to work and thus receiving much needed additional income to support family needs. Ingrid (aged 67) was a typical representative of her generation. She remembered having three options when she left school at the age of 15: shop, factory or office work. Her father would not let her work in a factory, and said she would be working 'all hours' at a shop, so office work was presented as the best option. Her mother took her to find an office job at a company where her brother was already employed, and she got a job there without being interviewed for it. Ingrid was expected to contribute for her board at the family home. Her mother also helped Ingrid to change jobs later on, by contacting someone she knew who then offered Ingrid a job. 'So I just went along, they weren't advertising', said Ingrid, who thought that it would be difficult to obtain a job in the same informal way today. Ingrid often wishes she had become a nurse, but reflects that she has had limited opportunities and choices. James (77) was another typical representative of the parent generation. The oldest of ten children, he left school at the age of 14 , and remembered that he had three choices when he was 15: iron works, upholstery or the railway. James made a conscious decision to go for what he perceived as the least risky employer, namely the railway, which was the biggest employer in the area. Moreover, his father, who already worked for the railway, helped him get a job by arranging an interview. James worked on the railway all his life. 
Many of the 'safe-players' reminisced about previous times when it was possible to obtain 'a job for life' upon entering the labour market. To them, a job for life presented something positive, as secure, long-term jobs enabled people to worry less about possible redundancies and unemployment. The interviewees clearly saw the option of having a job for life as something belonging to the past; as something rather unachievable in today's labour market.

Among the parent generation, the narratives were not permeated by any strong sense of risk in relation to entry into the labour market. Although options were in many cases limited, there were no instances where members of the parent generation were left with no choice at all. Furthermore, they were able to rely to a large extent on personal networks and in a few cases also on institutions like the Labour Exchange if such networks were nonexistent, when seeking entry to the labour market. Pathways to employment were thus usually determined by (limited) local opportunities and personal networks consisting of family and friends and their connections to local employers. ii Our findings complement those of previous research in emphasising the stability and security offered to young people entering the labour market through the guidance and opportunities provided by significant others such as family members or peers (Furlong and Cartmel 2007: 8). Major employers, such as the railway, or the mining and textile industries, gave young people the opportunity to enter the local labour market. Besides class background, options depended on what your local area could offer, as the geographical mobility of individuals was limited due to lack of transport and other factors. Mildred (68), for example, left school at 15, and was 
presented with only one option as her mother found her a job in a factory where her older sister already worked. As soon as Mildred grew in confidence and experience, however, she realised there were other factories in her area that offered better pay, and she actually found it easy to change jobs: 'Well, jobs were available then. I mean if you didn't like a job today you got another job tomorrow. It was, it was so easy'. There were three big factories in Mildred's local area, and the second job she found was at a factory where her aunt had previously worked. If you got a job at one of these factories, 'you'd got a job for life if you wanted it. Nowadays nobody can say that, that they've got a job for life because they haven't', said Mildred. The main driving force for labour market participation among study participants from the parent generation was financial need. Money to pay for housing, food and clothing for the family has been the most important employment outcome for this cohort. In other words, 'playing it safe' was considered the best course of action.

Paul (80) was one of the few individuals in our sample who had relied on institutional assistance to get jobs. He came from a small town and used the Labour Exchange twice to get jobs; the first time when leaving school at fourteen years of age and then again a few years later. Paul had limited job opportunities, but in hindsight he felt that the jobs he did have had been his choice, that he had made the right decisions, and that he had been in control of his career promotions and progression. Paul's case highlighted an important gender difference we found typical for this generation: it was primarily the men (and husbands) of the parent generation who felt in control of their decisions, even within the constraints of 
their local employment markets and the expectations of their own parents and peers. The women (and wives) had fewer options, were more strongly guided by tradition and their parents, and ultimately curtailed in their choices by their partners. The labour market also provided fewer opportunities, especially as these women had rarely benefited from more than the minimum of (compulsory) education. The parent generation in our sample was typically conscious of the structural constraints imposed on their career choices by their social background; that is, their need to secure an income for themselves and for their family. While social conditions forced both men and women to seek 'safe' employment, men, more so than women, described their efforts as seeking these opportunities pro-actively and portrayed their choices as primarily their own. Even though they presented what Beck describes as 'standard life histories' (Beck 2000: 70), it is important to note that 'playing it safe' also involves elements of choice, decision-making and control. Although a job for life and job security were clearly available in the Fordist era, people who entered and participated in the labour market at that time were also actively factoring in such elements in deciding on their course of action. They were acutely aware that choosing differently would increase the risk of instability and insecurity in terms of income.

Although the parent generation conceded that obtaining secure employment had become more difficult and employment itself more precarious for their children than had been the case for themselves, both women and, especially, men of this generation had been alert to the need for secure employment and sought to select employers on that basis. But this appeared easier to them than how they perceived their children's choices today. The parent generation 
was concerned about not going to work for the 'wrong' employer; someone whose business might go under, for whatever reason. Men appeared particularly sensitive to job insecurity, possibly because they sensed the effects job loss might have to their future role as breadwinners. This generation was aware of risk; that is, the risk of economic failure. But it also felt it was able to control this risk, which was calculable to the extent that the men and women felt able to judge if their (prospective) employer was of the kind that would remain in business for more than the foreseeable future, ideally for the duration of their working lives.

\section{Generational pathways to the labour market: The offspring generation}

Clear changes in people's approaches to job seeking and their work orientations had taken place by the time the offspring generation sought to enter the labour market. On the whole, the offspring generation reported less reliance on family, friends and institutions than we found among the parent generation in relation to entry to the labour market. More frequently than among the parent generation, the offspring generation perceived themselves as active decision-makers who were in charge of their careers. Only in a handful of cases were they 'playing it safe' by following traditional trajectories that primarily offered job security. Their biographical narratives were markedly suffused with the notion of an increase in individualised choice and responsibility in relation to labour market participation. Although having a wide range of opportunities was to some extent valued positively, many also felt overwhelmed by the (career) choices that they faced. 
Rebecca (23) was a typical representative of the offspring generation. After completing her university degree she had taken a job and deferred her plans for post-graduate education for a year. She had doubts about going back to university, as she also had ideas for a private business. She was constantly weighing her options: 'Should I, shouldn't I?'. She associated her indecision with the fact that she had lots of opportunities and options in terms of what direction to take. Although she appreciated having many options, it made it hard for her to choose a particular direction. Any and all choices would contribute to the making of her biography and self-identity. Rebecca was used to making her own decisions and liked to be in control of what she was doing. Her motive in seeking a job was to stay financially independent from a future husband, to enjoy a high standard of living, and to be a valued member of society. She saw herself as having more choices and options than her mother, to whom she made repeated references. The mother, Amelia (62), had been instructed by her father and cousin to work at a particular company after finishing compulsory schooling. Amelia's options had been further impeded by an early start to her own family and by her husband's expectations for her to be a housewife. Rebecca reflected that she did not want to find herself in a similar position to her mother, and insisted that she would make her own choices despite any objections or resistance from her parents. She was not sure if she was always choosing the right course of action, 'and sometimes it feels really risky, but it will always be something positive', said Rebecca. Another example of a discontinuity in outlooks between the parent and the offspring generation was that of Isabella (37) and her mother Ingrid (67), 
whom we described earlier. Similar to Amelia in the above example, Ingrid had experienced limited choice and opportunity in terms of labour market entry and participation. Unlike her daughter Isabella some decades later, Ingrid was comparatively resigned to this fact - if not content with it. Isabella, on the other hand, had been at the same company since leaving school at the age of 18 , but had been through numerous job changes and had taken on more and increasingly challenging responsibilities within the company. She was confident, had career aspirations, and cared a great deal about her own success. Her biographical narrative was suffused with the notion of individual agency and choice. She saw herself as having made opportunities for herself by taking risks within the company, by pushing herself forward to take on new roles and responsibilities. Her narrative was also contradictory, as she claimed not to think about the future. Yet she had balanced her career risktaking by obtaining some financial security through home ownership and a private pension. Isabella described herself as sensible in not spending everything she earned. Security was important to her, and she was keenly aware that her job might not be for life: "Work is something these days that is not a given, it's not a permanent [thing]...'. Although she cared about the financial security a job could and did give her, her driver for change was 'stimulation and challenge'. Self-satisfaction was thus a deeply rooted motivation in her work. She was also aware of the generational differences between herself and her mother: 'Because everything that I've said has been me, me, me, hasn't it?' Her mother, on the other hand, had always made her decisions with a view to other people around her, including husband and children. 
Peter (47), son of Paul (80), whom we met earlier, provided in many respects a contrast to Isabella. While Isabella had worked for the same company but in different and increasingly challenging roles over the years, Peter had been in and out of jobs with various employers. His father Paul had, we recall, found work through the Labour Exchange, while Peter, after obtaining a university degree, found it hard to get a job using the now typical means of newspaper job sections and jobcentres. He also found it difficult to choose what to do, and sent out applications for a range of different jobs. He had about fifty interviews before being offered his first job in which he stayed for three and a half years. He then changed job within the company and stayed another two and a half years before changing jobs again. He always worried about possible redundancy, and maintained a constant vigilance of the job market, 'just in case'. He described the last two and a half years at the company as a 'high anxiety period', with 'no feeling of job security'. He was eventually made redundant by the company he worked for next, and remained unemployed for a while. From then on, his career involved repeated moves between short, temporary contracts, and unemployment.

Despite his financial instability, however, Peter found it more important 'to have the right kind of job' than to receive the added benefits a job can offer (e.g., a company car or financial shares). Although it was important for him to work from an economic point of view, he would also have liked to be able 'to make a difference' through his job. In his current position he enjoyed job security, as he was working for a government agency. Feeling that something was missing, however, and that he needed more inspiration in his work, he was looking for a new job opportunity. As a consequence of the instabilities in 
his employment history, he found it difficult to trust anyone. He was very aware that the economy and market forces affected job seekers, and felt that he had 'been able to make the best decisions that the market has allowed'. He was adamant that he had made his own choices and not been influenced by family or friends, and that his decisions had been the best he could make at the time. Peter was thus caught between individualised responsibility, so typical of Beck's risk regime, and structural constraints placed on individual agency, or between what Beck calls the placing of each person's biography 'in his or her own hands, open and dependent on decisions' (Beck 1992: 135) and the constraints produced by the economy, the labour market and consumerism (ibid.: 131). In Peter's opinion, there was a lack of community networks in today's environment, and society had developed towards what he called 'self individualism'. In such a climate, and reflecting on his own experiences, Peter had come to take the view that 'the reality is that you can never be totally secure'. Having lost money on the sale of a property he once owned, he saw his pension fund and the prospect of inheriting his parents' house as providing long-term security. In his view he was not to be blamed for the 'bad timing' associated with his entry into the job market and subsequent job changes and property sale. Rather, these events had been marked by constraints produced by economic and societal factors.

Among the three examples we have used of individuals from the offspring generation, at 47, Peter was the oldest. Despite his wish to combine a selffulfilling career with a stable income, he had been unable to construct and develop the career track that Isabella had built for herself, after a period of indecision not dissimilar to Rebecca's current experience. While Peter did his 
best to obtain both interesting and secure jobs through actively and continuously seeking employment, his labour market participation is marked by periods of temporary and short-term employment, redundancies, and unemployment. Similar to Isabella, Peter has an individualistic outlook, in that he sees himself as having been responsible for his own life and for making his own decisions. Peter's narrative, however, is also marked by the importance of structural forces, as he sees 'market forces' or 'the economy' as having a decisive impact on his ability to create a continuous career for himself. In the end, therefore, although Peter accepts his own responsibility, he is also adamant that his options and opportunities have been severely limited by structural forces over which he has no control. A victim of circumstances, he has 'been able to make the best decision that the market has allowed'. A rather different offspring case was that of Ella (30). Up until recently, she had taken a very similar route into the labour market as her mother Mildred (68), discussed above, had some thirty years earlier. Up to that point, both had been 'safe-players'. As we saw earlier, Mildred had relied on family members in order to obtain jobs at factories in her local area, and her main driving force for paid employment was financial need. More recently, Mildred's husband had helped their daughter Ella find an office job after finishing a secretarial college course. The sentiment that ‘you get a job, it doesn't matter what it is as long as you're earning money' was passed down to her from her parents: 'Because with my family it was get a job, you know, you're ok as long as you get a job, it doesn't matter if you're not happy, it's money, you know'. At the time, Ella was not sure what she really wanted to do; she lacked selfconfidence and found that her options were limited. In hindsight, she regrets 
the fact that she comes from a working class background and is convinced this has limited her opportunities. For example, she has never been encouraged to go to university or to make her own decisions. Her parents have tried 'to help in their own way by trying to make the decisions for me and telling me what to do, that's their way of helping, which really is a hindrance because it's not let me make my own decisions and try things out for myself'. At the time of the interview, however, Ella had reached a turning point in her life, largely due to having developed a work-related illness and experiencing an employer that was unwilling to respond to her health problem. Supported by her doctor she handed in her notice and stayed at home with her small children for a while. She was now taking a college course and planning to do voluntary work and enrolled in further part-time education in order to fulfil her newly formed career aspirations. She was no longer interested in having a job just to earn money; she wanted to improve herself, improve her children's lives 'and probably help other people' as well, and she felt that she was exercising more agency than ever before through making her own decisions. There were still some constraining factors, such as having children and paying a mortgage, which she saw as reducing her opportunity to 'take chances'. She now rejected the values and outlooks she judged to have observed in her parents. Instead of taking a job just because it provided money, she found it important 'to go in the right direction now' and to 'break the cycle'.

Ella appeared to share some of Peter's philanthropic idealism, seeking selfimprovement, and possibly also family and community improvement - rather than (just) income - in a job. But Ella also appeared to share the 
determination of Rebecca and Isabella as she sought to break with the past her parents seem to have imposed upon her and to follow her own, newly discovered aspirations.

\section{Narrative Shifts and Continuities between Generations}

These brief but representative summaries of the narratives presented by the participants in our study highlight a remarkable shift in the experiences of labour market entry and the approaches with which individuals, faced with rather different choices, initiated their careers. Along with the accounts of these experiences, perceptions of past and present altered from labour market entry as an almost fixed trajectory to a - at least for some - variable, if not flexible development path that tolerated experimenting in options to a previously unknown degree. These accounts were grounded in different and at times novel perceptions of the scope for individual self-determination. Unlike the parent generation, there was no one dominant shared discourse to detect among the offspring generation, but the majority of them displayed elements of the 'planner' and 'surfer' narratives. This generation, if anything, appeared to be characterised by a diversity that occasionally paired with rootlessness. The rootlessness of 'surfers' was both geographical and developmental, marking a lack of fixation on (career) objectives in stark contrast to the purpose-driven accounts of some of their peers (the 'planners').

In our sample we encountered a self-confidence and assertiveness among the offspring generation that had rarely been recalled by the parent generation. This assertiveness was reflected in accounts of active individual 
decision-making, driven by aspirations for upward mobility, awareness of choices and options, desire for self-fulfilment in a career and a break from reliance on family and from family tradition. These individuals felt in control, they were planning for the future and ready to take risks to achieve their ambitions. Education played a key role in this, as did awareness of options and opportunities, something that had been denied many of the parent generation. Perhaps for this reason, the number of individuals who predominantly shared this discourse rose from only four among the parent generation to eight among the offspring generation.

However, as these numbers suggest, career driven, active decision-making was not the only type of risk discourse among the offspring generation. We also found the offspring generation characterising their early labour market experiences as often experimental, sometimes confusing and not infrequently resulting in reversions and 'corrections'. Thirteen of the offspring generation predominantly described their experiences as lacking a clear target to aim for, resulting in opportunistic drifting, a 'going with the flow' that grasped opportunities as they appeared - naturally unforeseen - without specific consideration for their effect on or contributions to the construction of careers in the long term. This was not the result of a lack of awareness of alternative options, but of a decision not to make use of them. This behavioural pattern was not exclusive to the offspring generation as also seven of the parent generation had, in their earlier careers, opted for this experimental strategy that allowed them to delay decisions about their eventual career destinations, even for several years. However, the presence of 'surfer' narratives increased markedly from one generation to the next. 
Among the parent generation, we found a majority of individuals who described their labour market entries as virtually pre-determined and their own development path as ultimately beyond their personal control. Not only were choices more limited than today (as acknowledged by this generation); participants from the parent generation often pointed out that they simply had not been aware of alternative options. Their reliance on family, friends and local institutions (such as the Labour Exchange) in obtaining their first - and later - jobs reflected the absence of known alternatives as much as they perpetuated this limited perspective. But this did not matter much, because, at the heart of their labour market choices was financial need, not the satisfaction of personal aspirations. Of course, the emerging post-war middle class of service workers generated new ambitions within a new economic environment, fostered by an expanding, but still exclusionary system of secondary education. For the majority of the parent generation in our sample, however, the primary risk concern was to keep control over everyday life basics such as provision of home and food for family. The future was not and could not be planned, although individuals were worried about it and felt disempowered by their own lack of control. This was the dominant discourse among eighteen of the 29 participants from the parent generation, with a further two participants displaying elements of this discourse. Among the offspring generation, this discourse was dominant among only seven of the 29 participants, with a further two displaying elements of this discourse. All members of the offspring generation displaying a 'safer' narrative were children of parents who presented similar narratives. With few exceptions the two generations of 'safe-players' shared similar working class locations and 
were predominantly early school leavers. Such continuities, however, neither imply a direct nor a wholesale transmission of values and outlooks, as there may be a mix of shared and not shared narrative elements from one generation to the next. Moreover, continuities may rather be a reflection of a shared socio-economic background (Scabini and Marta 2006: 85). In all, our sample contained comparatively few cases (10 pairs, or roughly one third of the sample) of fundamental cross-generational similarity in risk perception and career decision-making, whilst a further one third (10 pairs) displayed a mix of shared and not shared narrative elements, and the final one third (9 pairs) consisted of fundamentally dissimilar generational pairs that demonstrated discontinuities in risk perception and career decision-making. In eight of the nine dissimilar pairs the parent member displayed full or mixed 'safer' narratives, while none of the children in these pairs narrated similar orientations. Rather, these eight children were either predominantly 'surfers' (5) or 'planners' (3). Such juxtapositions between generations affirm the disjuncture within modernity posited by Beck (1992) between a 'collectivised past' and a present characterised by a heightened and individualised perception of risk. However, our empirical evidence of both cross-generational continuities and discontinuities indicates that the disjuncture is rather muddy and complex.

Just as the detection of continuity or similarity between generations is not synonymous with direct transmission of risk perceptions from one generation to the next, a lack of similarity does not necessarily imply failure of transmission (Scabini and Marta 2006: 87). It is likely that general societal changes in values, outlooks and practices from one generation to the next 
have a significant impact on generational changes that can be found within families. For example, structural changes in the labour market might facilitate changes in how individuals view opportunities and constraints in relation to their own labour market participation. Along these lines Furlong and Cartmel (2007: 2) argue that social structures continue to be important for individuals' life chances, but because such structures are increasingly obscured, people now perceive the world as more unpredictable and risky than before. Furthermore, we think it likely that even though a lack of similarity can be detected between parents and their offspring in relation to some of the values they attach to labour market participation (earning money versus self realisation), other values that are of importance to labour market attachment (work ethic, socialising with other people) seem to remain constant across generations. As stated earlier, all the participants in our study presented themselves as having a strong work ethic, even though the motivation to take on work seems to have developed from taking on paid work to provide for self and family to taking on paid work to fulfil personal aspirations and enhance personal life quality in combination with securing an income. A broader examination of values and outlooks would present a greater potential for generational transmission but remains outside the remits of our qualitative research.

\section{Conclusion}

In this article we have examined how people from different generations narrate their own life history in relation to risk perceptions and decisionmaking in the context of labour market entry and participation. Our 
observation is that important changes have taken place from one generation to the next, from more pre-determined trajectories for the parent generation to more individualised, flexible and open-ended trajectories for the offspring generation. Importantly, these changes are gradual and complex, as evidenced by the continuities and discontinuities identified in the biographical narratives of our research participants.

Among the older generation, and especially among those with a working class background, we found that individuals often used networks consisting of family members and friends, and in a few cases relied on institutional support from public job agencies, in order to obtain entry to the labour market. Many in the parent generation were happy to be in a 'job for life', as this provided a secure income. Money was most often the driving force for the parent generation's participation in the labour market. Although the local employment market and personal networks were important in determining their job opportunities, we found no pervasive sense of risk among members of the parent generation. In the words of one individual, John (74), 'there was always some sort of work'. In a sense it is community and family life, and aspirations in terms of earning your way and not being a burden on society that takes centre stage in the biographical narratives of the parent generation. Among the offspring generation, however, it is the individual that increasingly takes centre stage in the biographical narratives, supporting Beck and BeckGernsheim's view that individualisation both permits and demands active individual involvement (Beck and Beck-Gernsheim 2002: 4). The new generation has been presented with many more options and opportunities than the older generation, and this in turn has made it more difficult to choose 
any particular path. The development of self-identity and satisfaction seems to hinge on the ability to make the right choices in an often confusing world. This generation is risk aware, and individuals find themselves in a more or less constant self-doubt where they are unsure whether they are actually making the right choices. Individuals are also actively seeking and taking on risks as they may seize opportunities that come along. Risk awareness, however, does not necessarily imply risk preparedness, and many lament that they have no job security or investments for the future. For this generation, the labour market is constantly changing, and jobs are perceived as more volatile and less secure than in the past. Individualised biographies are being worked on and produced in an environment where the individual is still faced with structural constraints. These are no longer produced by the limits of local employment markets and personal networks of friends and family, but by the global economy, the demands of the labour market and consumerism (Beck 1992). Under such conditions, social relationships (including those in the labour market) can neither be dictated by others nor calculated in advance (Beck and Beck Gernsheim 2002: 151). The demands on the individual are 'overtaxing' and, as a rule, also 'ambivalent' (ibid.). Under pressure to conform to one or the other of the 'highly differentiated [...] function[s]' of risk society (ibid.), our offspring generation has developed diverse strategies to accommodate the normative ambivalence of society by way of avoidance or (imagined or factual) accommodation of these functions.

At the same time, societal changes towards individualisation and a lesser reliance on tradition appear to have influenced the ways in which members of the offspring generation have been met with more opportunities and also their 
increased ability to make individual choices. In some cases offspring have resisted parental influences through individual agency, but in this process they have been aided by societal changes in how we all apply for and obtain work. What is different for the offspring generation when compared to the parent generation is that their biographies are much more individualised and suffused with notions of agency and risk. Their social context is also more uncertain - not only has planning (active decision-making) become uncertain of its outcomes; 'safe-playing' hardly seems a viable alternative in a basically insecure (labour market) environment. Perhaps 'surfing' is the better option, as it is based on a flexible attitude to life and chances where 'the risk of taking a risk' is downplayed. Whereas the parent generation invoked a sense of risk in relation to the possible negative outcome of choosing the 'wrong employer' (and not in choosing between different alternatives), the current generation senses a more fundamental uncertainty - a randomness they feel unable to command - the only certainty is the absence of lasting conditions. Their coping method is self-belief and self-reliance - the repeated utterance of 'I can do it', 'my responsibility', 'my choice', 'my decision'. In this perspective there is hardly any room for structures (they have become invisible or obscured, as posited by Furlong and Cartmel 2007); individual agency is perceived as everything in a world fraught with insecurity. Functionally differentiated, risk society has become devoid of the shared and trusted orientations that would still have guided their parents' generation. For some, this leaves a vacuum of experience that may be replaced with selfgenerated ambition, that is, planning, progression and self-correction; while 
others seek identity in more experimental ways, through flexibility, adaptability and adjustment.

The offspring generation appears to have responded to these conditions of uncertainty with both (Beck's) re-flex and (Giddens') re-action. These people leapt at sudden opportunities or carefully planned their next strike. Following its erosion as the dominant behavioural concept, there has not been a wholesale replacement of 'safe-playing' by active planning and development of self-determined careers. Instead, 'surfing', experimenting, and 'going with the flow' has emerged alongside active planning and decision-making as a prominent strategy for career construction and identity formation. As Cebulla and Taylor-Gooby (2008) have shown, status enhancement and, albeit to a lesser extent, income generation, are losing importance as the main drivers of career building among the current generation of Britain's labour market entrants. In their place, we see new, sometimes idealistic, typically idiosyncratic and individualistic objectives emerging as the shapers of career decisions.

With status enhancement removed as the traditionally central career objective, re-flex as well as re-action become viable alternative options for constructing one's (career) biography in late modern risk society. Neither is a feature unique to risk society. Earlier generations also re-acted spontaneously, perhaps thoughtlessly, to career challenges and opportunities. Similarly, earlier generations also attempted to develop their career. What has changed is the framework and context in which re-flex and re-action occur. The demise of tradition has forced individualisation upon the current generation more so than any previous generation. Socio-economic change, 
or, to be precise, the regime of accelerated capitalist accumulation, has replaced calculable risk with uncertainty that cannot be forced into probability equations. In these circumstances, there are no more role models to follow, only case scenarios and biographies to adopt or develop. Whether this is done spontaneously, by re-flex, or purposefully, as re-action, depends on the constellation of circumstances that may fortuitously present themselves to the individual - or the social, human and financial capital that allows the young career seeker to project herself into a position of seemingly constructive planning and planned implementation. In the uncertainty of risk society, however, these two, chance and strategy, become indistinguishable.

\section{References}

Abbot, David, Deborah Quilgars and Anwen Jones (2006). "The Impact of Social and Cultural Difference in Relation to Job Loss and Financial Planning: Reflections on the Risk Society". Forum: Qualitative Social Research 7 (1), Art. 16.

Alexander, Jeffrey (1996). "Critical reflections on 'reflexive modernity”". Theory, Culture and Society 13 (4): 133-138.

Alexander, Jeffrey and Philip Smith (1996). "Social science and salvation:

Risk society as a mythic discourse". Zeitschrift fur soziologie 25 (4): 251-262. Beck, Ulrich (2000). The Brave New World of Work. Cambridge: Polity Press. Beck, Ulrich (1992). Risk society: Towards a new modernity. London: Sage. Beck, Ulrich and Elisabeth Beck-Gernsheim (2002). Individualization. Institutionalized Individualism and its Social and Political Consequences. London: Sage. 
de Beer, Paul (2007). "How individualized are the Dutch?", Current Sociology Cartmel, Fred (2004). "The labour market inclusion and exclusion of young people in rural labour markets in Scotland". In Wendy Mitchell, Robin Bunton and Elieen Green (eds.), Young people, risk and leisure. New York: Palgrave Macmillan: 75-93.

Cebulla, Andreas and Peter Taylor-Gooby (2008). Testing the Risk Society Hypotheses. ESRC Research Report, Award No. RES-000-22-1751.

Available at

http://www.esrcsocietytoday.ac.uk/esrcinfocentre/viewawardpage.aspx?award number=RES-000-22-1751.

Cunnigham, Michael (1991). At Home at the End of the World. Harmondsworth: Penguin.

Dohmen, Thomas, Armin Falk, David Huffman and Uwe Sunde (2006). The intergenerational transmission of risk and trust attitudes. IZA Discussion Paper No. 2380, October 2006. Bonn: Institute for the Study of Labour. Douglas, Mary and Aron Wildawsky (1982). Risk and culture. An essay in the selection and interpretation of technological and environmental dangers. Berkeley: University of California Press.

Furlong, Andy and Fred Cartmel (1997). Young People and Social Change. Individualization and risk in late modernity. Buckingham: Open University Press.

Furlong, Andy and Fred Cartmel (2007). Young People and Social Change. New Perspectives. $2^{\text {nd }}$ ed. Maidenhead: Open University Press. Giddens, Anthony (1991). Modernity and self-identity. Self and society in the late modern age. Stanford: Stanford University Press. 
Grieco, Margaret (1987). Keeping it in the family. Social networks and employment chance. London: Tavistock Publications.

Gustafson, Per E. (1998). "Gender differences in risk perception: Theoretical and methodological perspectives". Risk Analysis 18 (6): 805-811.

Heinz, Walter R. and Helga Krüger (2001). "Life Course: Innovations and Challenges for Social Research". Current Sociology 49 (2): 29-45. Henwood, Karen, Nick Pidgeon, Sophie Sarre, Peter Simmons and Noel Smith (2008). 'Risk, framing and everyday life. Epistemological and methodological reflections from three socio-cultural projects'. Health, Risk \& Society 10 (5): 421-438.

Kelly, Peter (2001). "Youth at risk: Processes of individualisation and responsibilisation in the risk society". Discourse: studies in the cultural politics of education 22 (1): 23-33.

Lasch, Christopher (1991). The attitude of narcissism: American life in an age of diminishing expectations. New York: W. W. Norton.

Lupton, Deborah (1999). Risk. London: Routledge.

MacEwen Scott, Alison, ed. (1994). Gender segregation and social change.

Oxford: Oxford University Press.

Mitchell, Wendy, Paul Crawshaw, Robin Bunton and Eileen Green (2001). "Situating young people's experiences of risk and identity". Health, Risk and Society 3 (2): 217-233.

Mythen, Gabe (2005). "Employment, individualization and insecurity: Rethinking the risk society perspective". The Sociological Review 53 (1): 129149. 
Mythen, Gabe (2004). Ulrich Beck: A critical introduction to the risk society. London: Pluto.

Oltedal, Sigve, Bjőrg-Elin Moen, Hroar Klempe and Torbjőrn Rundmo (2004). Explaining risk perception: An evaluation of cultural theory. Rotunde no. 85. Trondheim: Norwegian University of Science and Technology. Riessman, Catherine Kohler (1993). Narrative analysis. London: Sage. Roberts, Brian (2002). Biographical research. Buckingham: Open University Press.

Roberts, Ken (2001). Class in Modern Britain. New York: Palgrave.

Scabini, Eugenia and Elena Marta (2006). "Changing intergenerational relationship". European Review 14 (1): 81-98.

Tulloch, John and Deborah Lupton (2003). Risk and everyday life. London: Sage.

Turow, Scott (1991). The Burden of Proof. Harmondsworth: Penguin. Vickerstaff, Sarah (2006). "Life Course, Youth, and Old Age". In Peter TaylorGooby and Jens Zinn (eds.), Risk in Social Science. Oxford: Oxford University Press: 180-201.

Weber, Max (2001). The Protestant Ethic and the Spirit of Capitalism. London: Routledge.

Wilkinson, lain (2001). "Social theories of risk perception: At once indispensable and insufficient". Current Sociology vol. 49 (1): 1-22.

\footnotetext{
${ }^{i}$ For an overview and discussion of different class schemes used by sociologists, see Roberts 2001. For class distinctions based on occupational status see Roberts 2001 and http://www.statistics.gov.uk/methods quality/ns sec/continuity.asp.
} 
ii Cartmel (2004) has found the same to be true today among young people in rural labour markets in Scotland. Grieco (1987) has argued that kinship networks are particularly important for individuals from working class backgrounds who seek employment. 